\title{
Complete genome sequences of Francisella noatunensis subsp. orientalis strains FNO12, FNO24 and FNO190: a fish pathogen with genomic clonal behavior
}

\author{
Lucas Amorim Gonçalves ${ }^{1,2}$, Siomar de Castro Soares ${ }^{1}$, Felipe Luiz Pereira ${ }^{1}$, Fernanda Alves Dorella ${ }^{1}$, \\ Alex Fiorini de Carvalho ${ }^{1}$, Gabriel Magno de Freitas Almeida ${ }^{1}$, Carlos Augusto Gomes Leal ${ }^{1}$, Vasco Azevedo $^{2}$ \\ and Henrique César Pereira Figueiredo ${ }^{1^{*}}$
}

\begin{abstract}
The genus Francisella is composed of Gram-negative, pleomorphic, strictly aerobic and non-motile bacteria, which are capable of infecting a variety of terrestrial and aquatic animals, among which Francisella noatunensis subsp. orientalis stands out as the causative agent of pyogranulomatous and granulomatous infections in fish. Accordingly, F. noatunensis subsp. orientalis is responsible for high mortality rates in freshwater fish, especially Nile Tilapia. In the current study, we present the genome sequences of F. noatunensis subsp. orientalis strains FNO12, FNO24 and FNO190. The genomes include one circular chromosome of 1,859,720 bp, consisting of 32 \% GC content, 1538 coded proteins and 363 pseudogenes for FNO12; one circular chromosome of 1,862,322 bp, consisting of 32 \% GC content, 1537 coded proteins and 365 pseudogenes for FNO24; and one circular chromosome of 1,859,595 bp, consisting of 32 \% GC content, 1539 coded proteins and 362 pseudogenes for FNO190. All genomes have similar genetic content, implicating a clonal-like behavior for this species.
\end{abstract}

Keywords: Complete genome sequencing, Fish pathogen, Genetic clonal behavior

\section{Introduction}

In 1922, Edward Francis (1872-1957), an American bacteriologist, described the bacterium that causes tularemia in humans, Francisella tularensis. This bacterium is the most studied of its genus $[1,2]$. Until recently, the genus Francisella consisted of only two species: F. tularensis and F. philomiragia; however, new species and new strains were isolated, such as $F$. noatunensis and the subspecies $F$. noatunensis subsp. orientalis [1], the latter being recognized as one of the most important pathogens of cultured tilapia (Oreochromis spp.) [3].

F. noatunensis subsp. orientalis is the etiologic agent of pyogranulomatous and granulomatous infections in fish. In the last few years, $F$. noatunensis subsp. orientalishas

\footnotetext{
* Correspondence: figueiredoh@yahoo.com

${ }^{1}$ National Reference Laboratory for Aquatic Animal Diseases (AQUACEN), Ministry of Fisheries and Aquaculture, Federal University of Minas Gerais, Belo Horizonte, Brazil

Full list of author information is available at the end of the article
}

been responsible for a large number of deaths of tilapia and other freshwater species cultured in the United States, the United Kingdom, Japan, Taiwan, Jamaica, Costa Rica, Brazil and some other Latin American regions [4-6]. Nevertheless, besides infecting important cultivable species such as tilapia, threeline grunt (Parapristipoma trilineatum) and hybrid striped bass (Morone chrysops X Morone saxatilis), this bacterium is also capable of infecting wild fish such as guapote tigre (Parachromis managuensis) $[4,5]$.

Although the disease caused by this species presents with a high mortality rate during outbreaks and has been reported in several countries, the phylogenomic relationships among isolates from different countries and the evolutionary history of this pathogen are still poorly characterized. Therefore, the strains presented herein were isolated from three different regions and outbreaks to characterize the genetic diversity of the microorganism $F$. noatunensis subsp. orientalis strains FNO12, FNO24 and FNO190. 
Table 1 Classification and general features of Francisella noatunensis subsp. orientalis strains FNO12, FNO24 and FNO190 according to the MIGS recommendations [9]

\begin{tabular}{|c|c|c|c|}
\hline MIGS ID & Property & Term & Evidence code ${ }^{a}$ \\
\hline & \multirow[t]{8}{*}{ Classification } & Domain Bacteria & TAS [26] \\
\hline & & Phylum Proteobacteria & TAS [27] \\
\hline & & Class Gammaproteobacteria & TAS [28] \\
\hline & & Order Thiotrichales & TAS [29] \\
\hline & & Family Francisellaceae & TAS [30] \\
\hline & & Genus Francisella & TAS $[31,32]$ \\
\hline & & $\begin{array}{l}\text { Species Francisella } \\
\text { noatunensis subsp. orientalis }\end{array}$ & TAS [33] \\
\hline & & $\begin{array}{l}\text { Type strain FNO12, FNO24 } \\
\text { and FNO190 }\end{array}$ & IDA \\
\hline & Gram stain & Gram-negative & TAS [33] \\
\hline & Cell shape & pleomorphic & TAS [33] \\
\hline & Motility & Non-motile & TAS [33] \\
\hline & Sporulation & Not reported & NAS \\
\hline & $\begin{array}{l}\text { Temperature } \\
\text { range }\end{array}$ & Mesophilic $\left(15-34^{\circ} \mathrm{C}\right)$ & TAS [33] \\
\hline & $\begin{array}{l}\text { Optimum } \\
\text { temperature }\end{array}$ & $<25^{\circ} \mathrm{C}$ & TAS [33] \\
\hline & $\begin{array}{l}\text { pH range; } \\
\text { Optimum }\end{array}$ & Not reported & NAS \\
\hline & $\begin{array}{l}\text { Carbon } \\
\text { source }\end{array}$ & Not reported & NAS \\
\hline \multirow[t]{3}{*}{ MIGS-6 } & \multirow[t]{3}{*}{ Habitat } & FNO12 - Nile tilapia kidney & \multirow[t]{3}{*}{ NAS } \\
\hline & & FNO24 - Nile tilapia spleen & \\
\hline & & FNO190 - Nile tilapia spleen & \\
\hline MIGS-6.3 & Salinity & Not reported & NAS \\
\hline MIGS-22 & $\begin{array}{l}\text { Oxygen } \\
\text { requirement }\end{array}$ & Strictly aerobic & TAS [33] \\
\hline MIGS-15 & $\begin{array}{l}\text { Biotic } \\
\text { relationship }\end{array}$ & $\begin{array}{l}\text { Intracellular facultative } \\
\text { pathogen }\end{array}$ & TAS [7] \\
\hline MIGS-14 & Pathogenicity & Pathogenic for fish & TAS [7] \\
\hline \multirow[t]{3}{*}{ MIGS-4 } & \multirow[t]{3}{*}{$\begin{array}{l}\text { Geographic } \\
\text { location }\end{array}$} & $\begin{array}{l}\text { FNO12 - Brazil/State of Minas } \\
\text { Gerais/Areado city }\end{array}$ & \multirow[t]{3}{*}{ NAS } \\
\hline & & $\begin{array}{l}\text { FNO24 - Brazil/State of Minas } \\
\text { Gerais/Alterosa city }\end{array}$ & \\
\hline & & $\begin{array}{l}\text { FNO190 - Brazil/State of São } \\
\text { Paulo/Santa fé do Sul city }\end{array}$ & \\
\hline \multirow[t]{3}{*}{ MIGS-5 } & \multirow{3}{*}{$\begin{array}{l}\text { Sample } \\
\text { collection }\end{array}$} & FNO12- Mai 5, 2012 & \multirow[t]{3}{*}{ NAS } \\
\hline & & FNO24 - Mai 5, 2012 & \\
\hline & & FNO190 - Nov 10, 2013 & \\
\hline \multirow[t]{3}{*}{ MIGS-4.1 } & \multirow[t]{3}{*}{ Latitude } & $\mathrm{FNO} 12-21^{\circ} 21^{\prime} \mathrm{S}$ & \multirow[t]{3}{*}{ NAS } \\
\hline & & FNO24 $-21^{\circ} 14^{\prime} \mathrm{S}$ & \\
\hline & & FNO190 - $20^{\circ} 12^{\prime} \mathrm{S}$ & \\
\hline \multirow[t]{3}{*}{ MIGS-4.2 } & \multirow[t]{3}{*}{ Longitude } & $\mathrm{FNO} 12-46^{\circ} 08^{\prime} \mathrm{W}$ & \multirow[t]{3}{*}{ NAS } \\
\hline & & $\mathrm{FNO} 24-46^{\circ} 08^{\prime} \mathrm{W}$ & \\
\hline & & FNO190 - 50 50 $55^{\prime} \mathrm{W}$ & \\
\hline
\end{tabular}

Table 1 Classification and general features of Francisella noatunensis subsp. orientalis strains FNO12, FNO24 and FNO190 according to the MIGS recommendations [9] (Continued)

\begin{tabular}{ll}
\hline MIGS-4.4 Altitude & FNO12 $-\sim 1,006$ \\
& FNO24 $-\sim 848$ \\
& FNO190 -370
\end{tabular}

${ }^{a}$ Evidence codes - IDA Inferred from Direct Assay, TAS Traceable Author Statement (i.e., a direct report exists in the literature), NAS, Non-traceable Author Statement (i.e., not directly observed for the living, isolated sample, but based on a generally accepted property for the species, or an anecdotal evidence). These evidence codes are from the Gene Ontology project [11]

\section{Organism information Classification and features}

This Francisella genus, from phylum Proteobacteria, class Gammaproteobacteria, order Thiotrichales, and family Francisellaceae, is a strictly aerobic, non-motile, pleomorphic, and Gram-negative bacteria of $0.5-1.5 \mu \mathrm{m}$ (Table 1 and Fig. 1). It is negative for nitrate reduction as well as adonitol, arabinose, cellobiose, esculin, galacturonate, glucuronate, malonate, mannitol, melibiose, raffinose, rhamnose, palatinose, and 5-ketogluconate fermentation. In contrast, it has C14 lipase, cystine arylamidase, paraphenylalanine deaminase, tetrathionate reductase, trypsin, urease, valine arylamidase, $\alpha$-chymotrypsin, $\alpha$-fucosidase, $\alpha$-galactosidase, $\alpha$-mannosidase, and $\beta$-glucuronidase activity, as well as acid production from lactose. Additionally, it is positive for acid phosphatase, alkaline phosphatase, $\mathrm{C} 4$ and C8 esterase, lipase, naphtol-AS-BI-phosphohydrolase, $\beta$-lactamase activity, and acid production from maltose [7]. Using the 16S RNA sequences with 1516 bp of FNO12, FNO24, and FNO190 with the neighbor-joining method based on 1000 randomly selected bootstrap replicates of alignments using Mega6 software [8], a phylogenetic tree showing these strains positioned in a species-specific clade was constructed (Fig. 2).

\section{Genome sequencing information Genome project history}

In the present study, the nucleotide sequence of the $F$. noatunensis subsp. orientalis FNO12, FNO24 and FNO190 complete genomes was determined. Sequencing and assembly were performed by the National Reference Laboratory for Aquatic Animal Diseases, and annotation was performed by the Laboratory of Cellular and Molecular Genetics. Both laboratories are located at the Federal University of Minas Gerais, Belo Horizonte, Minas Gerais, Brazil. Source DNA of these three strains are available at culture collection of AQUACEN. Table 2 presents the project information and its association with MIGS version 2.0 compliance [9].

\section{Growth conditions and genomic DNA preparation}

F. noatunensis subsp. orientalis strains FNO12, FNO24 and FNO190 were isolated from three different outbreaks 


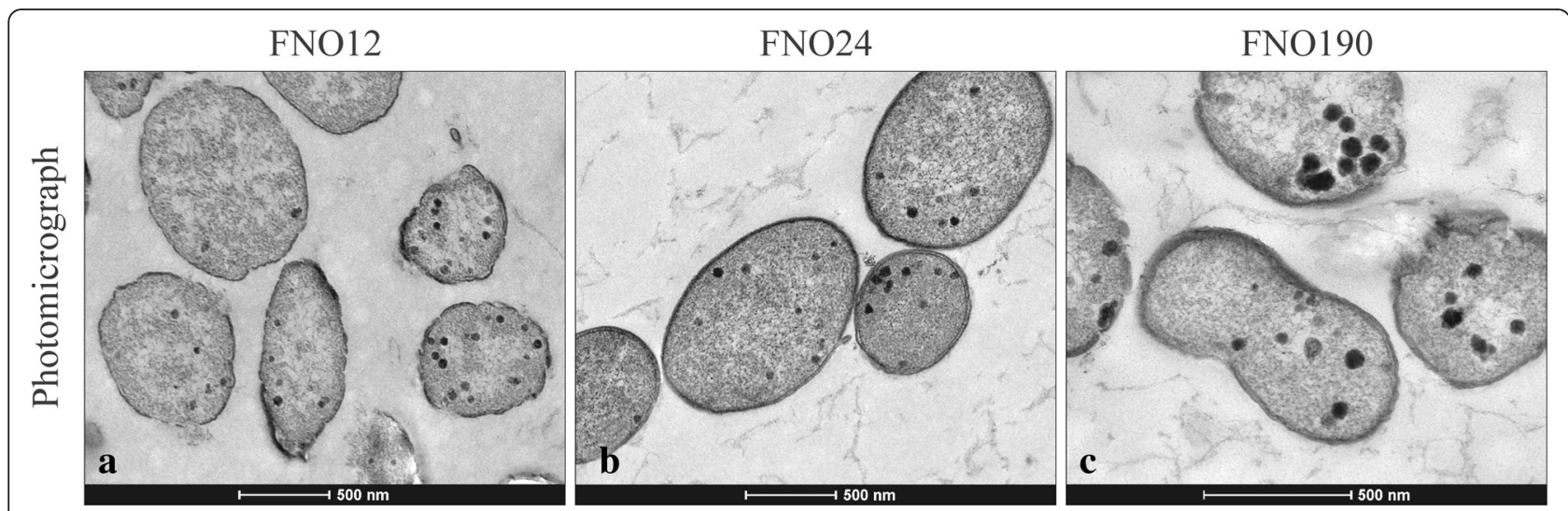

Fig. 1 Photomicrograph of the F. noatunensis subsp. orientalis strains. The strains FNO12, FNO24 and FNO190 are represented, respectively, by sections $\mathbf{a}, \mathbf{b}$ and $\mathbf{c}$

from Nile tilapia fish farms. Swabs of kidney (FNO12) and spleen (FNO24 and FNO190) tissues from each fish were sampled aseptically, streaked onto cysteine heart agar supplemented with $2 \%$ bovine hemoglobin (BD Biosciences, USA) and incubated at $28{ }^{\circ} \mathrm{C}$ for $4-7$ days [7]. The isolates were stored at $-80{ }^{\circ} \mathrm{C}$ in MuellerHinton cation-adjusted broth supplemented with $2 \%$ VX supplement (Laborclin, Brazil), $0.1 \%$ glucose, and $15 \%$ glycerol. The isolates were thawed, streaked onto $\mathrm{CHAH}$ and incubated at $28{ }^{\circ} \mathrm{C}$ for $48-72 \mathrm{~h}$. Genomic DNA was extracted by the use of the Maxwell $16^{\circ}$ Research Instrument (Promega, USA) according to the manufacturer's recommendations. Briefly, (i) $2 \times 10^{9}$ cells were lysed in the presence of a chaotropic agent and a detergent, (ii) nucleic acids were bound to silica magnetic particles, (iii) bound particles were washed and isolated from other cell components, and (iv) nucleic acids were eluted into a formulation for sequencing. Genomic DNAs were measured using Qubit 2.0 Fluorometer (Life Technologies, Thermo Scientific, USA) and yield of DNA were $64.8 \mathrm{ng} / \mu \mathrm{L}$ (FNO12), $58.0 \mathrm{ng} / \mu \mathrm{L}$ (FNO24) and $54.4 \mathrm{ng} / \mu \mathrm{L}$ (FNO190). Purity of DNAs (UV $\mathrm{A}_{260} / \mathrm{A}_{280}$ ) was accessed by NanoDrop 2000 Spectrophotometer (Thermo Scientific, USA). Ratios for each sample were 1.89, 1.95, and 1.96 for FNO12, FNO24 and FNO190, respectively. The extracted DNA was stored at $-80{ }^{\circ} \mathrm{C}$ until use.

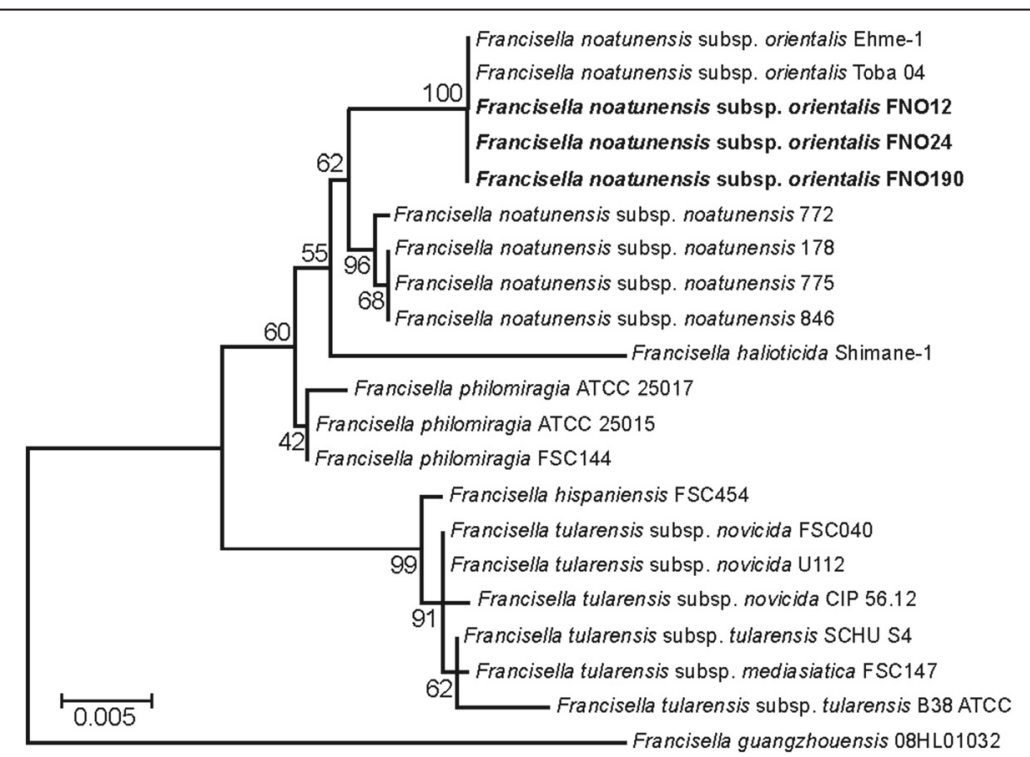

Fig. 2 Phylogenetic tree of the F. noatunensis subsp. orientalis strains. Phylogenetic tree of the F. noatunensis subsp. orientalis strains FNO12, FNO24 and FNO190 representing their relative position in the genus Francisella based on $16 \mathrm{~S}$ sequences. The statistical method used was maximum likelihood, and the bootstrap number was 1000. Thus, the values next to the nodes represent the percentage of the number of times, in 1000 repetitions, in which that clade was formed 
Table 2 Project information

\begin{tabular}{|c|c|c|c|c|}
\hline \multirow[t]{2}{*}{ MIGS ID } & \multirow[t]{2}{*}{ Property } & \multicolumn{3}{|l|}{ Term/Strains } \\
\hline & & FNO12 & $\mathrm{FNO} 24$ & FNO190 \\
\hline MIGS-31 & Finishing quality & Finished & Finished & Finished \\
\hline MIGS-28 & Libraries used & Fragment & Fragment & Fragment \\
\hline MIGS-29 & Sequencing platforms & Illumina MiSEQ & Ion Torrent PGM ${ }^{\mathrm{TM}}$ & Ion Torrent PGM ${ }^{T M}$ \\
\hline MIGS-31.2 & Fold coverage & 1382.15 & 79.82 & 203.43 \\
\hline MIGS-30 & Assemblers & Edena & Mira and Newbler & Mira and Newbler \\
\hline \multirow[t]{6}{*}{ MIGS-32 } & Gene calling method & RAST & RAST & RAST \\
\hline & Locus Tag & FNO12 & FNO24 & FNO190 \\
\hline & Genbank ID & СР011921 & CP011922 & СР011923 \\
\hline & Genome Database release & $2015 / 6 / 20$ & $2015 / 6 / 20$ & $2015 / 6 / 20$ \\
\hline & GOLD ID & Gb0109929 & Gb0109930 & Gb0109931 \\
\hline & BIOPROJECT & PRJNA232116 & PRJNA234502 & PRJNA240882 \\
\hline \multirow[t]{2}{*}{ MIGS-13 } & Source Material Identifier & FNO12 & $\mathrm{FNO} 24$ & FNO190 \\
\hline & Project relevance & $\begin{array}{l}\text { Fish pathogen } \\
\text { associated with } \\
\text { a large number } \\
\text { of deaths of tilapia } \\
\text { and other freshwater } \\
\text { species }\end{array}$ & $\begin{array}{l}\text { Fish pathogen } \\
\text { associated with } \\
\text { a large number } \\
\text { of deaths of } \\
\text { tilapia and other } \\
\text { freshwater species }\end{array}$ & $\begin{array}{l}\text { Fish pathogen } \\
\text { associated with } \\
\text { a large number } \\
\text { of deaths of } \\
\text { tilapia and other } \\
\text { freshwater species }\end{array}$ \\
\hline
\end{tabular}

\section{Genome sequencing and assembly}

The genome sequencing of the FNO12 strain was performed with the MiSEQ platform (Illumina ${ }^{\circ}$, USA), while the genome sequencing of the FNO24 and FNO190 strains was performed with the Ion Torrent Personal Genome Machine $^{\mathrm{Tm}}$ (Life Technologies, USA). MiSEQ used the Nextera DNA Library Preparation Kit while
PGM used the Ion PGM 200 bp Sequencing Kit. The quality of the raw data was analyzed using FastQC [10], and the assembly was performed using the Edena 2.9 [11], Mira 3.9 [12] and Newbler 2.9 (Roche, USA) as the applied $a b$ initio strategy. The assemblies of FNO12, FNO24 and FNO190 produced a total of 15, 57 and 16 contigs, respectively. The first strain resulted in $\sim 1382$ -

Table 3 Genome statistics

\begin{tabular}{|c|c|c|c|c|c|c|}
\hline \multirow[t]{3}{*}{ Attribute } & \multicolumn{4}{|l|}{ Strain } & & \\
\hline & \multicolumn{2}{|l|}{$\overline{\mathrm{FNO} 12}$} & \multicolumn{2}{|l|}{ FNO24 } & \multicolumn{2}{|l|}{ FNO190 } \\
\hline & Value & $\%$ of total ${ }^{a}$ & Value & $\%$ of total ${ }^{a}$ & Value & $\%$ of total ${ }^{a}$ \\
\hline Genome size (bp) & $1,859,720$ & 100.00 & $1,862,322$ & 100.00 & $1,859,595$ & 100.00 \\
\hline DNA coding (bp) & $1,348,998$ & 72.53 & $1,343,370$ & 72.13 & $1,350,675$ & 72.63 \\
\hline DNA G + C (bp) & 600,797 & 32.30 & 601,431 & 32.29 & 600,768 & 32.30 \\
\hline DNA scaffolds & 1 & 100.00 & 1 & 100.00 & 1 & 100.00 \\
\hline Total genes & 1,951 & 100.00 & 1,952 & 100.00 & 1,951 & 100.00 \\
\hline Protein coding genes & 1,538 & 78.83 & 1,537 & 78.73 & 1,539 & 78.78 \\
\hline RNA genes & 50 & 2.56 & 49 & 2.51 & 50 & 2.56 \\
\hline Pseudo genes & 363 & 18.60 & 365 & 18.62 & 362 & 18.55 \\
\hline Genes with function prediction & 1,280 & 65.60 & 1,282 & 65.67 & 1,280 & 65.60 \\
\hline Genes assigned to COGs & 1,327 & 68.01 & 1,327 & 67.98 & 1,326 & 67.96 \\
\hline Genes with Pfam domains & 1,562 & 80.06 & 1,564 & 80.12 & 1,561 & 80.01 \\
\hline Genes with signal peptides & 128 & 6.56 & 128 & 6.55 & 126 & 6.45 \\
\hline Genes with transmembrane helices & 531 & 27.21 & 531 & 27.20 & 534 & 27.37 \\
\hline CRISPR repeats & 0 & 0 & 0 & 0 & 0 & 0 \\
\hline
\end{tabular}

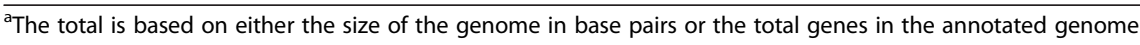


fold, coverage, the second had a value of $\sim 79$-fold, coverage, and the third had a value of 203-fold coverage,. Additionally, the strains FNO12, FNO24 and FNO190 presented an N50 value of 275,043 bp, 87,100 bp, and 237,022 bp, respectively. A super scaffold for FNO12 was produced with an optical map as a reference using restriction enzyme NheI, on MapSolver software (OpGen Technologies, USA). The remaining gaps were filled through the use of CLC Genomics Workbench 7 (Qiagen, USA) by mapping the raw data in gap flank repeated times until the overlap was found. For FNO24 and FNO190, the complete genome of FNO12 was used as a reference to construct the super scaffolds on CONTIGuator 2.0 software [13], and gap filling was conducted as described for strain FNO12. All the raw sequencing data were mapped onto the each final genome and the lack of contamination with other genomes were confirmed by the coverage and the low number of unmapped reads.

\section{Genome annotation}

Automatic annotation was performed using the RAST software [14]; tRNA and rRNA predictions were conducted using the tRNAscan-SE Search Server [15] and the RNAmmer [16], respectively. Manual curation of the annotation was done using Artemis software [17] and the UniProt database [18]. All putative frameshifts were manually curated based on the raw data coverage in CLC Genomics Workbench 7 software (Qiagen, USA), which was used to correct indel errors in regions of homopolymers.

\section{Genome properties}

The genomes are each comprised of a circular chromosome with sizes of $1,859,720 \mathrm{bp}, 1,862,322 \mathrm{bp}$, and 1,859,595 bp for FNO12, FNO24, and FNO190, respectively (Table 3). The GC content in the three strains is $32 \%$, and the number of pseudogenes is relatively high (363 on average).

Table 4 Number of genes associated with general COG functional categories

\begin{tabular}{|c|c|c|c|c|c|c|c|}
\hline \multirow[t]{3}{*}{ Code } & \multicolumn{6}{|l|}{ Strains } & \multirow[t]{3}{*}{ Description } \\
\hline & \multicolumn{2}{|l|}{$\mathrm{FNO12}$} & \multicolumn{2}{|l|}{ FNO24 } & \multicolumn{2}{|l|}{ FNO190 } & \\
\hline & Value & $\%$ age & Value & $\%$ age & Value & $\%$ age & \\
\hline J & 152 & 8.00 & 152 & 7.99 & 152 & 8.00 & Translation, ribosomal structure and biogenesis \\
\hline A & 1 & 0.05 & 1 & 0.05 & 1 & 0.05 & RNA processing and modification \\
\hline K & 47 & 2.47 & 47 & 2.47 & 47 & 2.47 & Transcription \\
\hline L & 74 & 3.89 & 74 & 3.89 & 74 & 3.89 & Replication, recombination and repair \\
\hline B & 0 & 0 & 0 & 0 & 0 & 0 & Chromatin structure and dynamics \\
\hline $\mathrm{D}$ & 16 & 0.84 & 16 & 0.84 & 16 & 0.84 & $\begin{array}{l}\text { Cell cycle control, Cell division, chromosome } \\
\text { partitioning }\end{array}$ \\
\hline V & 17 & 0.84 & 17 & 0.89 & 17 & 0.84 & Defense mechanisms \\
\hline $\mathrm{T}$ & 16 & 0.84 & 16 & 0.84 & 16 & 0.84 & Signal transduction Mechanisms \\
\hline M & 116 & 6.10 & 116 & 6.10 & 115 & 6.05 & Cell wall/membrane biogenesis \\
\hline $\mathrm{N}$ & 10 & 0.53 & 10 & 0.53 & 10 & 0.53 & Cell motility \\
\hline$U$ & 36 & 1.89 & 36 & 1.89 & 36 & 1.89 & Intracellular trafficking and secretion \\
\hline $\mathrm{O}$ & 68 & 3.58 & 68 & 3.57 & 68 & 3.58 & $\begin{array}{l}\text { Posttranslational modification, protein turnover, } \\
\text { chaperones }\end{array}$ \\
\hline C & 94 & 4.94 & 94 & 4.94 & 94 & 4.94 & Energy production and conversion \\
\hline G & 85 & 4.47 & 85 & 4.47 & 87 & 4.58 & Carbohydrate transport and metabolism \\
\hline $\mathrm{E}$ & 182 & 9.57 & 182 & 9.56 & 184 & 9.68 & Amino acid transport and metabolism \\
\hline $\mathrm{F}$ & 57 & 3.00 & 57 & 3.00 & 57 & 3.00 & Nucleotide transport and metabolism \\
\hline $\mathrm{H}$ & 80 & 4.21 & 80 & 4.20 & 80 & 4.21 & Coenzyme transport and metabolism \\
\hline I & 73 & 3.84 & 73 & 3.84 & 73 & 3.84 & Lipid transport and metabolism \\
\hline P & 74 & 3.89 & 74 & 3.89 & 76 & 4.00 & Inorganic ion transport and metabolism \\
\hline Q & 40 & 2.10 & 40 & 2.10 & 40 & 2.10 & $\begin{array}{l}\text { Secondary metabolites biosynthesis, transport and } \\
\text { catabolism }\end{array}$ \\
\hline R & 173 & 9.10 & 173 & 9.09 & 174 & 9.15 & General function prediction only \\
\hline S & 99 & 5.21 & 99 & 5.20 & 98 & 5.16 & Function unknown \\
\hline- & 574 & 30.19 & 576 & 30.27 & 575 & 30.24 & Not in COGs \\
\hline
\end{tabular}

${ }^{a}$ The percentage is based on the total number of protein coding genes in the annotated genome

${ }^{b}$ The total does not correspond to the final quantity of CDSs for each genome because some genes are associated with more than one COG functional category 
Strain FNO24 had more protein coding genes, and one RNA-coding gene fewer than the other two strains. For the FNO12 and FNO190 strains, 1280 genes were annotated with functional prediction, whereas for strain FNO24, 1282 genes were annotated. Each genome contained 621 CDSs classified as hypothetical proteins by the COG database [19]. Table 4 summarizes the number of genes associated with general COG functional categories. Figure 3 shows the comparison of FNO12 with FNO24, FNO190 (presented in this study) with the other two strains deposited in GenBank (F. noatunensis subsp. orientalis strains LADL-07-285A and Toba04, accession numbers: CP006875 and CP003402, respectively).

\section{Insights from the genome sequence}

A high similarity in the genetic content of these genomes was seen in Fig. 3. Additionally, Additional file 1 shows the only eight protein coding sequences with less than $99 \%$ identity between the three sequenced genomes (six hypothetical proteins, one Type IV pili, and one secreted protein). Also, this high intraspecies similarity (100.00 \pm $0 \%$ ) may be viewed in Additional file 2 and Additional file 3 using Gegenees [20] with threshold of $30 \%$ and Mauve [21] with progessiveMauve algorithm, respectively. These analyses include the three strains of this work and other three deposited at GenBank (FNO01, Toba04, and LADL-07-285A, GenBank nos. CP012153, CP003402, and CP006875, respectively) belonging to the same species. In contrast, the similarity with the subspecies F. noatunensis subsp. noatunensis is reduced to $84.09 \pm$ $0.40 \%$ (Additional file 2). Furthermore, the orthoMCL software [22] was used to predict the cluster of orthologous genes. CDSs shared by all species were considered to be part of the core genome, whereas CDSs harbored by only species were considered to be species-specific genes. There are 891 CDSs shared by all Francisella species (Fig. 4). Interestingly, the F. tularensis subsp. mediasiatica shows only 2 singleton CDSs, that because this species shared 1380 of yours 1385 CDSs with F. tularensis subsp. tularensis, whereas the $F$. noatunensis subsp. orientalis had 296 species-specific CDSs (Additional file 4 shows COG functional categories found of each CDS). Finally, the GIPSy software [23] was used to predict genomic islands present on $F$. noatunensis subsp. orientalis. FNO12 strain was chosen as query, whereas three strains of close related species was used as references $(F$. philomiragia subsp. philomiragia ATCC 25017, F. tularensis subsp. novicida U112, and Thiomicrospira crunogena

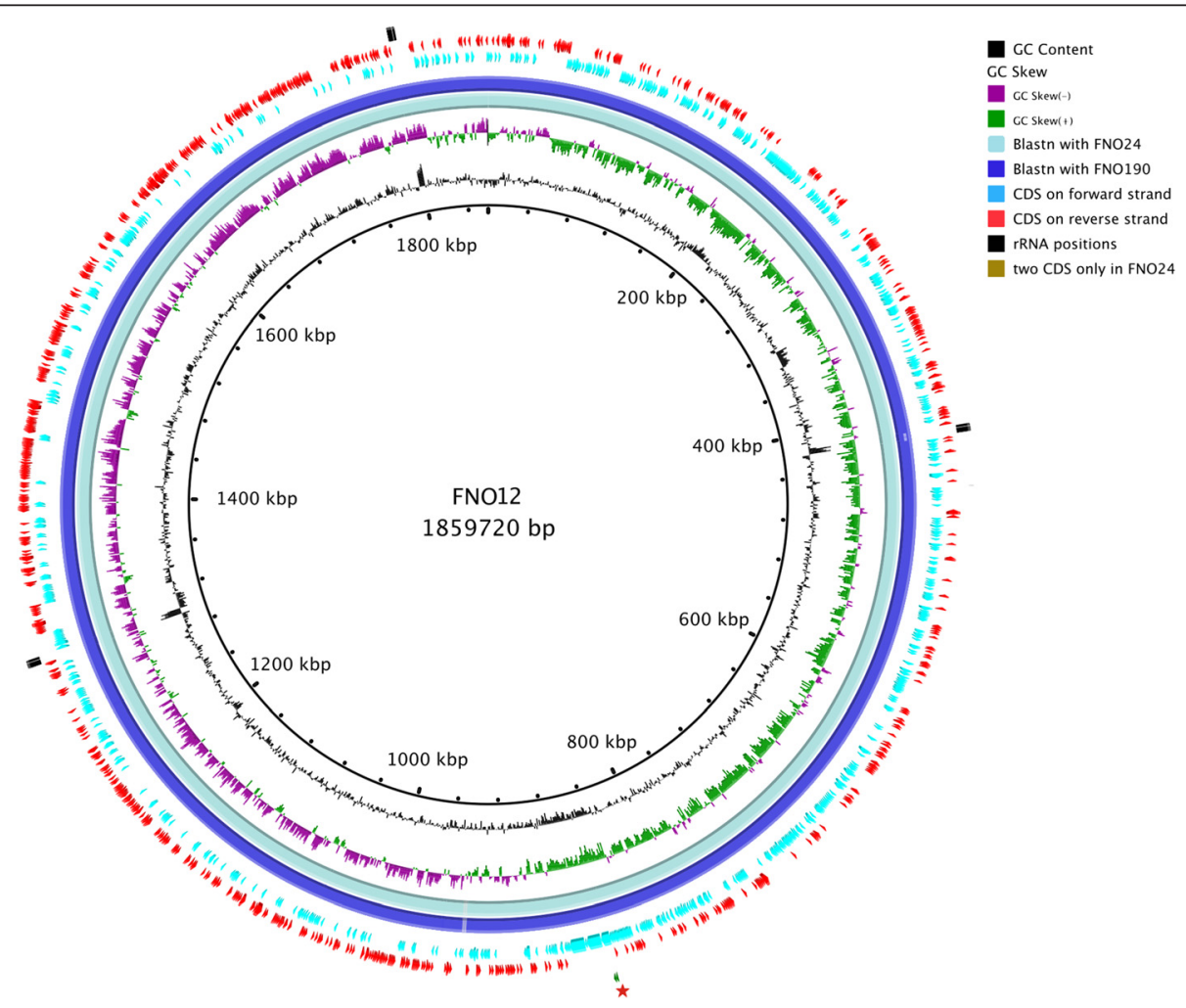

Fig. 3 Graphical circular map of F. noatunensis subsp. orientalis strain FNO12 in comparison with FNO24 and FNO190 (presented in this work) and LADL-07-285A and Toba04 (deposited in GenBank). From outside to the center: two CDSs only present in FNO24 (close to red star), tRNA positions, rRNA positions, CDSs on reverse strand, CDSs on forward strand, BlastN hits with Toba04 strain, BlastN hits with LADL-07-285A strain, BlastN hits with FNO190, BlastN hits with FNO24, GC skew and GC content 


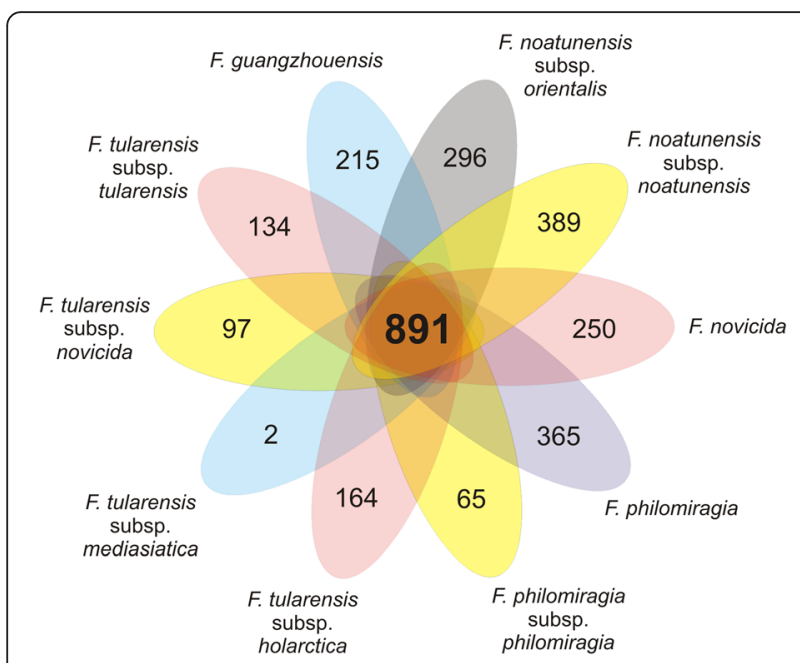

Fig. 4 Schematic view of the core genes and singletons of all Francisella species in orthoMCL analysis. The central number represents the core CDSs shared by all species, whereas the number on each branch shows the singletons of each species

XCL-2, GenBank nos. CP000937, CP000439, CP000109, respectively). Ten genomics islands were predicted by GIPSy, including 2 putative pathogenic islands (PAI1 and PAI2) and 1 putative resistance island (REI1), and plotted using BRIG software [24] (Additional file 5). GEI3 is, apparently, exclusive of $F$. noatunensis subsp. orientalis, and GEI4 is shared only with $F$. noatunensis subsp. noatunesis species, another species of marine environment. REI1 and PAI1 are partially shared by all species of Francisella genus. PAI2 is partially shared with all species of Francisella genus and totally shared with $F$. philomiragia and $F$. philomiragia subsp. philomiragia species. GEI6, predicted only as genomic island by GIPSy, contains the genes $m l t A$, rplM, rpsI, mglA, mglB, rnhB, yfhQ, ptsN, mnmE, cysK, $p d p A, p d p B$, iglD, iglC, iglB, iglA, $p d p D$, anmK, related with the Francisella Pathogenicity Island, a previously described pathogenic island for the Francisella genus [25]. Further studies are required to characterize these genomic islands, since the GIPSy analysis suggests a greater number of Horizontal Gene Transfer than previously described for this species.

\section{Conclusions}

Three genomes of an important fish pathogen are presented in this work. Despite being isolated from different outbreaks and from different host organs, they are very similar considering the brief analysis of this work. All analyses suggest the clonality of the strains with minor differences in the quantity of pseudogenes and the number of CDSs and RNAs. Furthermore, the high number of pseudogenes present in all sequenced strains corroborate that this species is undergoing genome decay [1].

\section{Additional files}

Additional file 1: Alignment of proteins coding sequences with less than $99 \%$ identity between the three sequenced genomes. (TXT 20 kb)

Additional file 2: Heat map showing high similarity between the sequenced genemes performed in Gegenees software with threshold of $30 \%$. (TIF $984 \mathrm{~kb}$ )

Additional file 3: Synteny analysis of Francisella noatunensis subsp. orientalis FNO01, FNO12, FNO24, FNO190, Toba04 and LADL-07-285A strains performed with Mauve software with progessiveMauve algorithm. (TIF $381 \mathrm{~kb}$ )

Additional file 4: COG functional categories found of each speciesspecific CDS of Francisella noatunensis subsp. orientalis. (TXT $16 \mathrm{~kb}$ )

Additional file 5: The genomic islands predicted by GIPSy software (2 putative pathogenic islands, 1 putative resistance island, and 7 uncharacterized genomic island), plotted using BRIG software. (TIF 2066 $\mathrm{kb})$

\section{Abbreviations}

CDS: coding sequence; $\mathrm{CHAH}$ : cysteine heart agar supplemented with hemoglobin; PGM: personal genome machine; rRNA: ribosomal RNA; tRNA: transporter RNA.

\section{Competing interests}

The authors declare that they have no competing interests.

\section{Authors' contributions}

$L A G$, SCS and FLP drafted the manuscript. FAD, AFC and GMFA performed the laboratory experiments. LAG, SCS, FLP, FAD and AFC sequenced, assembled and annotated the genome. CAGL, VACA and HCPF worked on the conception, design, and coordination of this study and helped to write the manuscript. All authors read and approved the final manuscript.

\section{Acknowledgements}

This work was supported by Conselho Nacional de Desenvolvimento Científico e Tecnológico (CNPq), Ministério da Pesca e Aquicultura and Fundação de Amparo à Pesquisa do Estado de Minas Gerais (FAPEMIG). We also acknowledge support from the Coordenação de Aperfeiçoamento de Pessoal de Nível Superior (CAPES).

\section{Author details}

${ }^{1}$ National Reference Laboratory for Aquatic Animal Diseases (AQUACEN), Ministry of Fisheries and Aquaculture, Federal University of Minas Gerais, Belo Horizonte, Brazil. 'Laboratory of Cellular and Molecular Genetics (LGCM), Federal University of Minas Gerais, Belo Horizonte, Brazil.

Received: 21 July 2015 Accepted: 5 April 2016

Published online: 12 April 2016

\section{References}

1. Sridhar S, Sharma A, Kongshaug H, Nilsen F, Jonassen I. Whole genome sequencing of the fish pathogen Francisella noatunensis subsp. orientalis Toba04 gives novel insights into Francisella evolution and pathogenecity. BMC Genomics. 2012. doi:10.1186/1471-2164-13-598.

2. Soto E, Kidd S, Mendez S, Marancik D, Revan F, Hiltchie D, Camus A. Francisella noatunensis subsp. orientalis pathogenesis analyzed by experimental immersion challenge in Nile tilapia, Oreochromis niloticus (L.). Vet Microbiol. 2013;164(1-2):77-84

3. Soto E, Revan F. Culturability and persistence of Francisella noatunensis subsp. orientalis (syn. Franciesella asiatica) in sea-and freshwater microcosms. Micro Ecol. 2012;63(2):398-404.

4. Soto E, Illanes O, Hilchie D, Morales JA, Sunyakumthorm P, Hawke JP, Goodwin A E, Riggs A, Yanong R P, Pouder D B, Francis-Floyd R, Arauz M, Bogdanovic L, Castillo-Alcala. Castillo-Alcala. Molecular and immunohistochemical diagnosis of Francisella noatunensis subsp. orientalis from formalin-fixed, paraffin-embedded tissues. J Vet Diagn Invest. 2012; 24(5):840-5. 
5. Soto E, Abrams SB, Revan F. Effects of temperature and salt concentration on Franciella noatunensis subsp. orientalis infections in Nile tilapia Oreochrimis niloticus. Dis Aquat Organ. 2012;101(3):217-23.

6. Leal CAG, Tavares GC, Figueiredo HCP. Outbreaks and genetic diversity of Francisella noatunensis subsp. orientalis isolated from-raised Nile tilapia (Oreochomis niloticus) in Brazil. Genet Mol Res. 2014;13(3):5704-12.

7. Birkbeck TH, Feist SW, Verner-Jeffreys DW. Francisella infections in fish and shellfish. J Fish Dis. 2011;34(3):173-87.

8. Tamura K, Stecher G, Peterson D, Filipski A, Kumar S. MEGA6: Molecular Evolutionary Genetics Analysis Version 6.0. Mol Biol Evol. 2013;30:2725-9.

9. Field D, Garrity G, Gray T, Morrison N, Selengut J, Sterk P, et al. The minimum information about a genome sequence (MIGS) specification. Nat Biotechnol. 2008. doi:10.1038/nbt1360.

10. FastQC. Babraham Bioinformatics. http://www.bioinformatics.babraham.ac. uk/projects/fastac (2015). Accessed 16 Set 2015.

11. Hernandez D, François P, Farinelli L, Osteras SJ. De novo bacterial genome sequencing: millions of very short reads assembled on a desktop computer. Genome Res. 2008. doi:10.1101/gr.072033.107.

12. Chevreux B, Wetter T, Suhai S. Genome Sequence Assembly Using Trace Signals and Additional Sequence Information. Comput Sci Biol Proc German Conf Bioinformatics. 1999:99:45-56.

13. Galardini M, Biondi EG, Bazzicalupo B, Mengoni A. CONTIGuator: a bacterial genomes finishing tool for structural insights on draft genomes. Source Code Biol Med. 2011. doi:10.1186/1751-0473-6-11.

14. Aziz RK, Bartels D, Best AA, et al. The RAST Server: rapid annotations using subsystems technology. BMC Genomics. 2008. doi:10.1186/1471-2164-9-75.

15. Schattner P, Brooks AN, Lowe TM. The tRNAscan-SE, snoscan and snoGPS web servers for the detection of tRNAs and snoRNAs. Nucleic Acid Res. 2005. doi:10.1093/nar/gki366.

16. Lagesen K, Hallin P, Rodland EA, Staerfeldt H, Torbjørn R, Ussery DW. RNAmmer: consistent and rapid annotation of ribosomal RNA genes. Nucleic Acids Res. 2007. doi:10.1093/nar/gkm160.

17. Rutherford K, Parkhill J, Crook J, et al. Artemis: sequence visualization and annotation. Bioinformatics. 2000;16:944-5.

18. Uniprot DB. UniProt Consortium. http://www.uniprot.org/(2015). Accessed 16 Set 2015.

19. Tatusov RL, Koonin EV, Lipman D. A genomic perspective on protein families. Science. 1997. doi:10.1126/science.278.5338.631.

20. Agren J, Sundström A, Håfström T, Segerman B. Gegenees: fragmented alignment of multiple genomes for determining phylogenomic distances and genetic signatures unique for specified target groups. PLoS One. 2012;7:e39107.

21. Darling AE, Mau B, Perna NT. progressiveMauve: multiple genome alignment with gene gain, loss and rearrangement. PLoS One. 2010;5:e11147.

22. Li L, Stoeckert CJJ, Roos DS. OrthoMCL: identification of ortholog groups for eukaryotic genomes. Genome Res. 2003;13:2178-89.

23. Soares SC, Geyik H, Ramos RTJ, Sá PHCG, Barbosa EGV, Baumbach J, et al. GIPSy: Genomic Island prediction software. J Biotechnol. 2015. doi:10.1016/j. jbiotec.2015.09.008.

24. Alikhan N, Petty NK, Ben Zakour NL, Beatson SA. BLAST Ring Image Generator (BRIG): simple prokaryote genome comparisons. BMC Genomics. 2011;12:402.

25. Hare RF, Hueffer K. Francisella novicida Pathogenicity Island Encoded Proteins Were Secreted during Infection of Macrophage-Like Cells. PLoS ONE. 2014. doi:10.1371/journal.pone.0105773.

26. Woese CR, Kandler O, Wheelis ML. Towards a natural system of organisms: Proposal for the domains Archaea, Bacteria, and Eucarya. Proc Nat Acad Sci. 1990;87:4576-9.

27. Garrity GM, Bell JA, Lilburn TG. Phylum XIV. Proteobacteria phyl. nov. In: Garrity GM, Brenner DJ, Krieg NR, Staley JT, editors. Bergey's Manual of Systematic Bacteriology, Volume 2. 2nd edition, Part B. New York: Springer; 2005. p. 1.

28. Garrity GM, Bell JA, Lilburn TG. Class III. Gammaproteobacteria class. nov. In: Garrity GM, Brenner DJ, Krieg NR, Staley JT, editors. Bergey's Manual of Systematic Bacteriology, Volume 2. 2nd edition, Part B. New York: Springer; 2005. p. 1.

29. Garrity GM, Bell JA, Lilburn TG. Order V. Thiotrichales ord. nov. In: Garrity GM Brenner DJ, Krieg NR, Staley JT, editors. Bergey's Manual of Systematic Bacteriology, Volume 2. 2nd edition, Part B. New York: Springer; 2005. p. 1.

30. Sjöstedt AB. Family III. Francisellaceae fam. nov. In: Garrity GM, Brenner DJ, Krieg NR, Staley JT, editors. Bergey's Manual of Systematic Bacteriology, Volume 2. 2nd edition, Part B. New York: Springer; 2005. p. 199-200.

31. Dorofe'ev KA. Classification of the causative agent of tularemia. Symposium Research Works Institute Epidemiology and Microbiology Chita. 1947;1:170-80.
32. Skerman VBD, McGowan V, Sneath PHA. Approved lists of bacterial names. Int J Syst Bacteriol. 1980;30:225-420.

33. Ottem KF, Nylund A, Karlsbakk E, Friis-Moller A, Kamaishi T. Elevation of Francisella philomiragia subsp. noatunensis to Francisella noatunensis comb. nov. [syn. F piscicida Ottem et al. (2008) syn. nov.] and characterization of $F$ noatunensis subsp. orientalis subsp. nov., two important fish pathogens. J Appl Microbiol. 2009. doi:10.1111/j.1365-2672.2008.04092.x.

\section{Submit your next manuscript to BioMed Central and we will help you at every step:}

- We accept pre-submission inquiries

- Our selector tool helps you to find the most relevant journal

- We provide round the clock customer support

- Convenient online submission

- Thorough peer review

- Inclusion in PubMed and all major indexing services

- Maximum visibility for your research

Submit your manuscript at www.biomedcentral.com/submit
) Biomed Central 